GUT

ONLINE

\title{
Combination Of Gastric Atrophy, Reflux Symptoms And Histological Subtype Indicates Two Distinct Aetiologies Of Gastric Cardia Cancer
}

Mohammad H. Derakhshan, Reza Malekzadeh, Hirotsugu Watabe, Abbass

Yazdanbod, Valerie Fyfe, Abbass Kazemi, Nasser Rakhshani, Reza Didevar, Masoud Sotoudeh, Abbass Zolfeghari and Kenneth McColl

Gut published online 26 Oct 2007;

doi:10.1136/gut.2007.137364

Updated information and services can be found at:

http://gut.bmj.com/cgi/content/abstract/gut.2007.137364v1

These include:

Email alerting Receive free email alerts when new articles cite this article - sign up in the box at the service top right corner of the article

Notes

Online First contains unedited articles in manuscript form that have been peer reviewed and accepted for publication but have not yet appeared in the paper journal (edited, typeset versions may be posted when available prior to final publication). Online First articles are citable and establish publication priority; they are indexed by PubMed from initial publication. Citations to Online First articles must include the digital object identifier (DOIs) and date of initial publication.

To order reprints of this article go to:

http://journals.bmj.com/cgi/reprintform

To subscribe to Gut go to:

http://journals.bmj.com/subscriptions/ 


\title{
COMBINATION OF GASTRIC ATROPHY, REFLUX SYMPTOMS AND HISTOLOGICAL SUBTYPE INDICATES TWO DISTINCT AETIOLOGIES OF GASTRIC CARDIA CANCER
}

\footnotetext{
Derakhshan M. ${ }^{1,2}$, Malekzadeh $\mathbf{R}^{2}$, Watabe $\mathbf{H}^{1}$, Yazdanbod A ${ }^{3}$, Fyfe ${ }^{1}$, Kazemi $A^{2}$, Rakhshani $\mathbf{N}^{4}$, Didehvar $\mathbf{R}^{3}$, Sotoudeh $\mathbf{M}^{2}$, Zolfeghari $\mathbf{A}^{3}$, McColl K.E.L ${ }^{1}$

${ }^{1}$ Section of Gastroenterology, Division of Cardiovascular and Medical Sciences, University of Glasgow, Glasgow

${ }^{2}$ Digestive Disease Research Centre, Medical Sciences, University of Tehran, Tehran

${ }^{3}$ Medical Faculty, Ardabil University of Medical Sciences, Ardabil

${ }^{4}$ Gastroenterology and Liver Research Centre, Iran University of Medical Sciences, Tehran
}

\author{
Correspondence to: \\ Professor K.E.L. McColl \\ Section of Gastroenterology \\ Division of Cardiovascular and Medical Sciences \\ Western Infirmary, University of Glasgow \\ Glasgow, G11 6NT, UK \\ E mail: k.e.l.mccoll@clinmed.gla.ac.uk
}




\section{ABSTRACT}

INTRODUCTION

Atrophic gastritis is a risk factor for non-cardia gastric cancer, and gastro-oesophageal reflux disease (GORD) for oesophageal adenocarcinoma. The role of atrophic gastritis and GORD in the aetiology of adenocarcinoma of the cardia remains unclear. We have investigated the association between adenocarcinoma of the different regions of the upper gastrointestinal tract and atrophic gastritis and GORD symptoms.

\section{METHODS}

138 patients with upper GI adenocarcinoma and age and sex matched controls were studied. Serum pepsinogen I/II was used as a marker of atrophic gastritis and categorised to five quintiles. History of GORD symptoms, smoking and H.pylori infection was incorporated in logistic regression analysis. Lauren classification of gastric cancer was used to subtype gastric and oesophageal adenocarcinoma.

\section{RESULTS}

Non-cardia cancer was associated with atrophic gastritis but not with GORD symptoms; $55 \%$ of these cancers were intestinal subtype. Oesophageal adenocarcinoma was associated with GORD symptoms, but not with atrophic gastritis; $84 \%$ were intestinal subtype. Cardia cancer was positively associated with both severe gastric atrophy [OR, 95\% Cl: $3.92(1.77-8.67)$ ] and with frequent GORD symptoms [OR, 95\% Cl: $10.08(2.29-44.36)]$ though the latter was only apparent in the nonatrophic subgroup and in the intestinal subtype. The association of cardia cancer with atrophy was stronger for the diffuse versus intestinal subtype and this was the converse of the association observed with non-cardia cancer.

\section{CONCLUSION}

These findings indicate two distinct aetiologies of cardia cancer, one arising from severe atrophic gastritis and being of intestinal or diffuse subtype similar to non-cardia cancer, and one related to GORD and intestinal in subtype, similar to oesophageal adenocarcinoma. Gastric atrophy, GORD symptoms and histological subtype may distinguish between gastric versus oesophageal origin of cardia cancer. 


\section{INTRODUCTION}

There has been substantial progress in our understanding of the aetiology of adenocarcinoma of the stomach and oesophagus over recent decades. Most cancers of the mid and distal stomach are a long-term complication of $H$. pylori-induced superficial gastritis. They arise in the subgroup of subjects in whom the superficial gastritis progresses to atrophic gastritis and intestinal metaplasia accompanied with loss of gastric acid secreting capacity ${ }^{(1,2)}$ H. pylori-induced atrophic gastritis and hypochlorhydria are strong risk factors for both the intestinal and diffuse histological subtype of gastric cancer. ${ }^{(2,3-6)}$ Another important independent risk factor for gastric cancer is smoking.(7-9) The fall in incidence of adenocarcinoma of the stomach in the Western world over recent decades may be attributable in part to a falling incidence of both $H$. pylori infection and smoking ${ }^{(6,10)}$

A major risk factor for adenocarcinoma of the oesophagus is gastro-oesophageal reflux disease.(11) The risk of oesophageal adenocarcinoma increases with both the frequency and duration of reflux symptoms ${ }^{(11-13)}$ Frequent reflux of gastric juice containing acid, pepsin and bile is thought to induce columnar and intestinal metaplasia of the squamous mucosa of the distal oesophagus. ${ }^{(14,15)}$ This metaplastic or Barrett's oesophagus has a markedly increased risk of progressing to adenocarcinoma of the intestinal histological subtype ${ }^{.(16)}$ In contrast to adenocarcinoma of the mid and distal stomach, that of the oesophagus is negatively associated with $H$.pylori infection. ${ }^{(17)}$ The mechanism of this negative association is unclear but might be related to a healthy acid secreting stomach being required to provide a refluxate of sufficient acidity to induce oesophageal damage.(18)

The aetiology of adenocarcinoma of the cardia and gastro-oesophageal junction is unclear and controversial. Understanding its aetiology is important as most adenocarcinomas of the upper gastrointestinal tract in the western world and in Northwest Iran involve the cardia and GE junction. ${ }^{.(19,20)}$ The association of cardia cancer with $H$. pylori infection is confusing with some studies showing a negative association, some a positive and some no association.(21-27) Some studies indicate that reflux symptoms are a risk factor for cardia cancer but a weaker risk factor than for oesophageal adenocarcinoma' ${ }^{(28)}$ A number of studies demonstrate smoking to be a risk factor for cardia cancer ${ }^{(9,29)}$

We recently studied the association between cancer of the cardia and serological evidence of both $H$. pylori infection and atrophic gastritis ${ }^{\left({ }^{(30)}\right.}$ This was performed in a nested case control study. We observed a negative association with H.pylori infection but a positive association between atrophic gastritis and cardia cancer in those with the infection. We interpreted this as indicating dual aetiology of cardia cancer with some cases being due to $H$. pylori-induced atrophic gastritis and aetiologically resembling adenocarcinoma of the mid and distal stomach and others being of a different aetiology and associated with a nonatrophic stomach. This latter group might be aetiologically similar to oesophageal adenocarcinoma.

In the current study we extended our investigation of the aetiology of cardia cancer by examining the association of both serological evidence of gastric atrophy and reflux symptoms with adenocarcinoma of the oesophagus, cardia and non-cardia regions of the stomach. This has been performed for the different histological subtypes of the cancer. We have also included H.pylori status and smoking history which are other well established risk factors for upper GI cancer. This has been undertaken in a population in Northwest Iran with a high incidence of upper gastrointestinal cancer ${ }^{(20,31)}$ Our studies examining the association with both atrophic gastritis and reflux symptoms provide substantial support for cardia cancer being of two distinct aetiological subtypes, one similar to non-cardia cancer and the other similar to oesophageal adenocarcinoma. 


\section{METHOD \& MATERIALS}

This was a case-control study, conducted in Aras Clinic in Ardabil province in Northwest Iran. The area is a well-known high risk region for gastric cancer in general and gastric cardia cancer in particular. Aras Clinic is a referral centre for delivery of investigational, therapeutic and preventative services to all patients with upper gastrointestinal tract disease throughout the Ardabil province. It is specifically equipped and staffed through government funding to conduct research into the aetiology of upper Gl cancer. According to the latest estimates from the Ardabil Cancer Registry ${ }^{(32)}$, half of all incident upper gastrointestinal cancers diagnosed in Ardabil province are recorded and evaluated in this Centre. The present study has been conducted by collaboration between the University of Glasgow (UK), Digestive Disease Research Centre (DDRC) of University of Tehran and Ardabil University of Medical Science.

In total, 152 consecutive eligible patients with gastric or oesophageal adenocarcinoma were identified. We excluded $14(9 \%)$ eligible patients for the following reasons: poor cooperation of patient due to severity of the illness $(n=4)$, patient refusal $(n=3)$ and insufficient or inappropriate serum or histologic samples $(n=7)$. Finally, 138 patients with gastric and oesophageal adenocarcinoma were enrolled into the study including 66 non-cardia, 53 cardia and 19 oesophageal adenocarcinoma. Diagnosis of cancer was made by microscopic verification of multiple endoscopic biopsies and all histologic slides were studied by two certified pathologists (N.R and R.D) and reviewed by third pathologist (M.S) to ensure meeting the protocol requirements in accordance with ICD-O-2. (33) In controversial cases, diagnosis of cancer was made only after joint agreement of all three pathologists Cardia cancer was defined as tumours whose main bulk was within $2 \mathrm{~cm}$ distal to the gastro-oesophageal junction. Tumours located completely above the gastrooesophageal junction were considered to be oesophageal in origin. Tumours located anywhere in the stomach other than the cardia were called non-cardia gastric cancer. The histological subtypes according to the Lauren classification were also recorded ${ }^{(34)}$

Prior to endoscopy, each patient had a standardised interview and details recorded regarding symptoms of reflux and smoking. The average frequency of heartburn and/or acid regurgitation over the five years prior to presentation excluding those of last one year before diagnosis of cancer was recorded. History of smoking was recorded as number of cigarettes per day and duration of smoking in years. Alcohol consumption is extremely rare in this region. The questionnaire employed was validated in a pilot study. ${ }^{(35)} \mathrm{A}$ fasting blood sample was collected from each patient before endoscopy and serum stored at $-70 \mathrm{C}$ for later serologic assessment.

In format of frequency-matched case control design, one control for each case of noncardia and cardia cancer and two controls for oesophageal adenocarcinoma patients were selected randomly from dyspeptic patients. They were attending the same Centre and their endoscopy had shown no evidence of peptic ulcer or tumours. The controls were sex and age matched within 4 years. The controls had undergone a similar interview to the cases and had also had serum stored prior to their endoscopy.

Serum pepsinogen I (PG I) and pepsinogen II (PG II) were assayed with enzyme immuno-sorbant assay (ELISA) methods using monoclonal antibodies to pepsinogen I and II (BIOHIT diagnostics, Biohit LTD, UK). All procedures were done according to manufacture's instructions and results of PG I and PG II reported in $\mu \mathrm{g} / \mathrm{L}$. PG I/II ratio was calculated and reported in fraction. We used serum PG I/II less than 2.5 as a serologic marker of atrophy as previously reported ${ }^{(30)}$ 
H.pylori infection was assessed by a serologic test using anti H.pylori Ig $\mathrm{G}$ antibody, supplied by the same manufacturer. A response titer more than 30 enzyme immuno units (EIU) was considered as positive for H.pylori infection.

\section{Statistical Analysis}

Serum PG I/II as serologic marker of atrophy were presented in quintiles. The PG I/II data of each control group were used to make quintiles. Using binary logistic regression, relationship of PG I/II quintiles with each cancer was estimated as odds ratio (OR) with their $95 \%$ confidence interval and related $p$ values. PG $1 / I$ quintiles were treated as a categorical variable and $5^{\text {th }}$ quintile was used as referent. Smoking, GORD symptoms and H.pylori serology were used as possible risk factors of cancer in univariate logistic regression. These variables were also used in multivariate model along with PG I/II quintiles. Smoking was presented as a dichotomous variable ( $1=$ Smoker: $\geq 10$ cigarettes per day for at least 10 years and no more than 5 years passed since stopping smoking, and $0=$ non-smoker including never smokers and those who smoked less than limits stated above). GORD symptoms were categorised as $0=$ never or less than one time per week, $1=$ one to two times per week, and $2=$ more than two times per week. In order to evaluate association of gastric atrophy with risk of different histological subtypes of upper Gl adenocarcinoma, we used the serum PG I/II less than 2.5 as a serologic marker of atrophy. Two sided $p$ values less than 0.05 were considered statistically significant. The SPSS statistical software version 14.0 was used for most analysis. ${ }^{(36)}$

\section{RESULTS}

Gastric non-cardia cancer: A total of 66 patients (49 male and 17 female, mean age $65.9+6.5$ ) with non-cardia cancer and similar number of controls were studied (Table 1). A monotonous decreasing risk of cancer was observed from the lowest to the highest quintiles of PG I/II (Fig 1a). In univariate analysis, the risk was maximal in patients with PG I/II $\leq 2.01$ with $\mathrm{OR}=15.76$ (3.92 - 63.43). Smoking also increased the risk of non-cardia cancer with $\mathrm{OR}=2.22$ (1.11 - 4.46) (table 2). GORD symptoms in both frequency levels showed a negative relationship with non-cardia cancer, but the association was only statistically significant in patients with GORD symptoms occurring 1-2 times per week. H.pylori seropositivity was detected in $93.9 \%$ of cases and $74.2 \%$ of controls and increased the risk of non-cardia in univariate analysis with $\mathrm{OR}=2.22(1.11-4.46)$.

In multivariate analysis including smoking, GORD symptoms and H.pylori sero-status, first and second lowest PG I/II quintiles increased the risk of cancer with ORs $(95 \% \mathrm{Cl})$ : $21.47(2.90-158.76)$ and $9.08(1.10-75.29)$, respectively. Smoking showed a more potent relationship with risk of non-cardia cancer, with OR $(95 \% \mathrm{Cl}): 5.83(2.11-16.11)$, GORD symptoms 1-2 times per week continued to show an inverse relationship, with OR (95\% Cl): 0.31 (0.11 - 0.85), The positive relationship between H.pylori infection and noncardia cancer no longer reached statistical significance OR (95\% Cl): $1.53(0.57-4.14)$.

According to the Lauren histological sub-classification of the non-cardia cancers, 36 (54.5\%) were intestinal subtype, 25 (37.9\%) diffuse, and $5(7.6 \%)$ cases mixed or unclassifiable. The intestinal subtype adenocarcinoma showed strong positive association with gastric atrophy (defined as PGI/II < 2.5) with OR $(95 \% \mathrm{Cl})$ : $13.02(4.39-38.61)$ in multivariate analysis. The diffuse subtype cancer was also associated less strongly with gastric atrophy with OR $(95 \% \mathrm{Cl}): 3.07$ (1.23 - 7.67). 
Oesophageal adenocarcinoma: 19 cases of oesophageal adenocarcinoma (12 male and 7 female, mean age $63.9+4.7)$ were compared with double the number of controls (Table 1). In univariate analysis, GORD symptoms, in category of $>2$ times per week increased the risk of cancer with $\mathrm{OR}(95 \% \mathrm{Cl})$ of $28.05(4.74-165.91)$. In multivariate analysis, involving PG I/II, smoking and H.pylori sero-status, this relationship showed a decrease as OR (95\% Cl): $12.46(1.80-86.47)$, (Table 3). Smoking also showed a positive relationship with the cancer, with OR $(95 \% \mathrm{Cl}): 4.56(1.01-20.68)$ which was not affected by other risk factors. There was no association between oesophageal adenocarcinoma and atrophy. Frequency of H.pylori infection in patients with oesophageal adenocarcinoma was lower than their matched controls (47.4\% vs. $73.7 \%)$. While inverse relationship between H.pylori and oesophageal adenocarcinoma was evident by univariate analysis (OR; $95 \% \mathrm{Cl}$ : $0.25 ; 0.08-0.75)$, this negative relationship lost its statistical significance in multivariate analysis (OR; $95 \% \mathrm{Cl}$ : $0.43 ; 0.10-1.91)$. By the Lauren histologic classification, $16(84.2 \%)$ of the 19 oesophageal adenocarcinomas were intestinal subtype.

Gastric cardia cancer: We studied 53 cases of cardia cancer (37 male and 16 female, mean age $63.8+7.1$ ) and the same number of controls (Table 1). A relationship between lowest quintile of PG I/II $(\leq 2.37)$ and cardia cancer was noted in multivariate analysis [OR (95\% Cl): 3.92 (1.77-8.67)], (Table 4). However, there was a heterogenic relationship between atrophy and risk of cardia cancer with a relatively quadratic trend of risk of cardia cancer against different quintiles of PG I/II (Fig. 1b). This contrasted with the linear association of non-cardia cancer with atrophy (Fig 1a). There was also a positive association between cardia cancer and GORD symptoms at the level of $>2$ times per week having an OR (95\% Cl): 10.08 (2.29 - 44.36). No significant effect of smoking was detected in our patients [OR $(95 \% \mathrm{Cl}): 1.40(0.56-3.51)]$. While serologic H.pylori infection was more frequent in cases than controls $(83.0 \%$ vs. $73.6 \%)$, there was no significant relationship between cardia cancer and H.pylori infection [(OR (95\% Cl): $2.42(0.84-7.02)]$.

We further investigated the nature of the dual association of cardia cancer with atrophy and GORD using the dichotomised values. The association between risk of cardia cancer and atrophy based on dichotomised definition PG I/II $<2.5$, showed a significant relationship with OR $(95 \% \mathrm{Cl}): 3.05(1.32-7.06)$. GORD symptoms dichotomised into >2 times/week versus $0-2$ times /week also showed a positive relationship with risk of cardia cancer with OR $(95 \% \mathrm{Cl}): 4.40$ (1.34-14.43). In order to further evaluate the relationship between atrophy, GORD and risk of cardia cancer, we recalculated the association of GORD and cardia cancer risk separately in atrophic and non-atrophic subgroups. This showed that the risk of cardia cancer was increased by GORD symptoms in non-atrophic patients, OR $(95 \% \mathrm{Cl}): 8.02(2.25-28.58)]$, but not in atrophic patients (Fisher exact test $\mathrm{p}$ value $=1.00)$. (Table 5, Fig 2).

In the cardia, $34(64.2 \%)$ of tumours were classified histologically as intestinal subtype, $16(30.2 \%)$ were diffuse subtype and only 3 cases were mixed subtype or unclassifiable. Both the intestinal subtype and diffuse subtype were associated with gastric atrophy, OR $(95 \% \mathrm{Cl}): 3.64$ (1.33-9.97), and OR (95\% Cl):17.71 (3.66-85.76) respectively.

The association of cardia cancer with GORD symptoms was also related to the histological subtype. The intestinal subtype cardia cancer showed significant relationship with presence of GORD symptoms >2 times per week with OR (95\% Cl): 5.86 (1.68-20.39). In contrast, the association between GORD symptoms and diffuse subtype statistically was not significant [OR (95\% Cl): $2.83(0.56-14.24)$ ]. 


\section{DISCUSSION}

In our subjects with non-cardia gastric cancer, we found a strong association between serological evidence of gastric atrophy and risk of cancer and this is consistent with many previous studies ${ }^{.37,38)}$ Atrophic gastritis was associated with increased risk of both the intestinal and diffuse histological subtypes of non-cardia cancer but the association was stronger for the former as previously reported $(37,39,40)$ Whereas, the intestinal subtype is nearly always a consequence of atrophic gastritis and intestinal metaplasia, the diffuse histological subtype sometimes develops in a non-atrophic stomach with a strong genetic predisposition being an important factor in some of these cases ${ }^{.(41,42)}$

An association between $H$. pylori infection and non-cardia cancer was present in the univariate analysis consistent with previous reports ${ }^{(2)}$. However, this association was lost in multivariate analysis when atrophy and lifestyle factors were included. This is consistent with $H$. pylori-induced atrophic gastritis being the pre-cancerous lesion rather than $H$. pylori infection itself. High prevalence of H.pylori infection in the background population shown in the current and previous studies can explain its weak relationship with gastric cancer risk. ${ }^{(43)}$

There was no significant association between frequent GORD symptoms ( $>2$ times/week) and non-cardia cancer in our study. However, the negative association between lees frequent GORD and non-cardia cancer can be explained by the atrophic gastritis protects against GORD symptoms, but it difficult to understand why this would not also protect against more frequent GORD.

We found that smoking was also a risk factor for non-cardia cancer as previously reported. The extent of the association in univariate analysis [OR $(95 \% \mathrm{Cl}): 2.22(1.11$ 4.46)] is consistent with most previous reports, suggesting smoking as a mild to moderate risk factor of non-cardia gastric cancer $(8,44,45)$. Incorporating atrophy, $H$. pylori status and GORD symptoms into multivariate analysis enhanced the effect of smoking [OR (95\%): 5.83 (2.11-16.11)]. This indicates that the effect of smoking is not mediated through induction of atrophy but acts independent of the atrophic process.

In contrast to non-cardia cancer, oesophageal adenocarcinoma was positively associated with reflux symptoms. This is consistent with previous reports and the currently accepted hypothesis that gastro-oesophageal reflux causes columnar and intestinal metaplasia which then progresses to intestinal subtype adenocarcinoma ${ }^{(11,46)}$ Consistent with this, the great majority of oesophageal adenocarcinomas in our study were of the intestinal histological subtype. There was also a positive association with smoking as previously reported. ${ }^{(44,47)}$ There was no association with gastric atrophy.

The main purpose of our study was to investigate the aetiology of cardia cancer and its relation to that of non-cardia and oesophageal adenocarcinoma. Cardia cancer showed a complex relationship with gastric atrophy. Severe gastric atrophy indicated by the lowest pepsinogen I/II quintile of $<2.37$ was associated with an increased risk of cardia cancer. However, unlike non-cardia cancer, there was no evidence of a progressive rise in cancer incidence with falling pepsinogen I/II ratio. Rather, the relationship between pepsinogen I/II ratio and cancer risk showed a quadratic pattern with the risk of cardia cancer being highest for the lowest and highest pepsinogen I/II ratios and lowest for the intermediate ratios. A plausible explanation for this complex association between cardia cancer and atrophic gastritis is that there are two distinct aetiologies of cardia cancer, one subgroup being associated with severe atrophic gastritis and resembling non-cardia cancer and the other subgroup unassociated or negatively associated with atrophic gastritis and aetiologically resembling oesophageal adenocarcinoma. 
Reflux symptoms were also found to be a risk factor for cardia cancer with GORD symptoms of $>2$ time per week increasing the risk of cardia cancer with OR $(95 \% \mathrm{Cl}): 10.08$ (2.29-44.36). Reflux symptoms have been reported previously to be a risk factor for cardia cancer but not as strong a risk factor as for oesophageal adenocarcinoma.(28) In our study, we were able to investigate the interaction of reflux symptoms and atrophy in the aetiology of cardia cancer. This showed that reflux symptoms were associated with cardia cancer only in non-atrophic subjects, with a powerful OR $(95 \% \mathrm{Cl}): 8.02(2.25-28.58)$. This is again consistent with two distinct aetiologies of cardia cancer, one being associated with atrophic gastritis and resembling non-cardia cancer and one associated with reflux and resembling oesophageal adenocarcinoma.

Further evidence of two distinct aetiologies of cardia cancer was apparent on examining the atrophy-cancer and GORD-cancer associations separately in the two histological subtypes. The association between atrophy and intestinal subtype adenocarcinoma was weaker in the cardia than in the non-cardia region of the stomach. This is consistent with the intestinal subtype cardia cancer being a mixture of tumours positively associated with atrophy (similar to non-cardia intestinal subtype adenocarcinomas) and tumours unassociated or negatively associated with atrophy (similar to oesophageal intestinal subtype adenocarcinoma).

The association of atrophy with diffuse cancer was stronger in the cardia than in the noncardia region of the stomach. This difference may be related to the different topographic distribution and extent of atrophy required to produce cancer at those two sites and the ability of PGI/II to detect the atrophy associated with cancer at these two sites. Atrophy tends to start in the distal stomach at the junction between the antrum and body mucosa and progress proximally ${ }^{(48,49)}$ Cancers tend to develop within atrophic mucosa and thus cancers of the distal stomach may develop in subjects with less extensive atrophy than would be required to produce cancer up at the cardia region. Furthermore, PGI/II is a reliable marker for detecting extensive atrophy involving the body mucosa but a poor marker for detecting early atrophy or that confined to the antral mucosa. ${ }^{(50,51)}$

The association between GORD symptoms and cardia adenocarcinoma was also related to the histological subtype. GORD symptoms were strongly associated with the intestinal subtype cancers at the cardia and this relationship was similar to that for oesophageal adenocarcinoma. This association with GORD symptoms and intestinal subtype adenocarcinoma at the cardia is consistent with some of these cancers occurring by the same mechanism as oesophageal adenocarcinoma which is also of the intestinal subtype; the reflux of gastric juice leading to columnar intestinal metaplasia, dysplasia and adenocarcinoma. In contrast, there was no relationship between GORD symptoms and diffuse subtype adenocarcinomas at the cardia.

Our findings thus support two distinct aetiologies of cardia cancer. One subtype is associated with atrophic gastritis and may be of the intestinal, diffuse or mixed histological subtype. It resembles non-cardia cancer and is likely to have arisen by the same process i.e. H. pylori-induced atrophic gastritis. The other subtype is associated with GORD and is of the intestinal histological subtype. It is likely to have a similar aetiology to oesophageal adenocarcinoma and to have arisen from acid reflux induced columnar intestinal metaplasia of original oesophageal squamous epithelium.

The above observations imply that there are not only two distinct aetiologies of cardia cancers but that the structural and functional state of the stomach associated with them is profoundly different. One type is associated with a non-atrophic healthy gastric mucosa producing sufficient acid and pepsin to damage the mucosa of the gastro-oesophageal junction and lead to columnar intestinal metaplasia and intestinal subtype cancer. The 
other is associated with atrophic gastritis of sufficient severity and extent to involve the proximal stomach leading to the development of intestinal or diffuse subtype cancer from the atrophic gastric mucosa.

It is very difficult pre-operatively, during surgery or even at post-mortem examination to determine whether cancer of the cardia has arisen from original gastric or oesophageal mucosa. Our study points to three factors likely to be useful in determining the origin of the cancer: (i) the histological subtype of the tumours, (ii) the state of the gastric mucosa distant from the tumour and (iii) the frequency of GORD symptoms (Fig. 2). Diffuse histological tumour subtype strongly indicates gastric origin. Intestinal subtype tumours with nonatrophic gastric mucosa and frequent GORD symptoms are highly likely to be of oesophageal origin. Intestinal subtype tumours with atrophic gastric mucosa and less frequent GORD symptoms are likely to be gastric in origin. It is difficult to classify a proportion of the intestinal type cardia cancer. This might be improved by more precise means of assessment of GORD and more accurate determination of the presence/absence of gastric atrophy, i.e. by histology of gastric mucosal biopsies.

\section{Acknowledgment:}

We are grateful to Professor John $\mathrm{H}$. McColl, Department of statistics, University of Glasgow for his invaluable statistical advice. Our special thanks goes to Dr Shahnam Arshi, head of the Ardabil University of Medical Sciences for his kind executive support and all Aras Clinic and DDRC's research staff for their help throughout the study.

\section{Competing Interest: non to declare}

The Corresponding Author has the right to grant on behalf of all authors and does grant on behalf of all authors, an exclusive licence (or non-exclusive for government employees) on a worldwide basis to the BMJ Publishing Group Ltd and its Licensees to permit this article to be published in Gut editions and any other BMJPGL products to exploit all subsidiary rights, as set out in our licence http: // gut.bmjjournals.com / ifora / licence.pdf 


\section{References:}

1. Correa P, Haenszel W, Cuello C, Tannenbaum S, Archer M. A model for gastric cancer epidemiology._Lancet. 1975 Jul 12;2(7924):58-60.

2. Uemura N, Okamoto S, Yamamoto S, et al. Helicobacter pylori infection and the development of gastric cancer. N Engl J Med. 2001 Sep 13;345(11):784-9.

3. Asaka M, Kimura T, Kato M, et al. Possible role of Helicobacter pylori infection in early gastric cancer development. Cancer.1994 Jun 1;73(11):2691-4.

4. Hansson LR, Engstrand L, Nyren O, et al. Prevalence of Helicobacter pylori infection in subtypes of gastric cancer. Gastroenterology.1995 Sep;109(3):885-8.

5. Parsonnet J, Friedman GD, Orentreich N, et al. Risk for gastric cancer in people with CagA positive or CagA negative Helicobacter pylori infection. Gut.1997 Mar;40(3):297301.

6. Kitahara F, Kobayashi K, Sato T, et al. Accuracy of screening for gastric cancer using serum pepsinogen concentrations. Gut.1999 May;44(5):693-7.

7. Nishino Y, Inoue M, Tsuji I, et al. Tobacco Smoking and Gastric Cancer Risk: An Evaluation Based on a Systematic Review of Epidemiologic Evidence among the Japanese Population. Jpn J Clin Oncol. 2006 Dec;36(12):800-7.

8. Sjodahl K, Lu Y, Nilsen TI, et al. Smoking and alcohol drinking in relation to risk of gastric cancer: a population-based, prospective cohort study. Int J Cancer 2007 Jan 1;120(1):128-32.

9. Gonzalez CA, Pera G, Agudo A, et al. Smoking and the risk of gastric cancer in the European Prospective Investigation Into Cancer and Nutrition (EPIC). Int J Cancer. 2003 Nov 20;107(4):629-34.

10. Rios-Castellanos E, Sitas F, Shepherd NA, et al. Changing pattern of gastric cancer in Oxfordshire. Gut.1992 Oct;33(10):1312-7.

11. Lagergren J., Bergström R., Lindgren A., et al. Symptomatic gastroesophageal reflux as a risk factor for esophageal adenocarcinoma. N Engl J Med 1999; 340:825-831.

12. Anandasabapathy $\mathrm{S}$, Jhamb J, Davila M, et al. Clinical and endoscopic factors predict higher pathologic grades of Barrett dysplasia. Cancer. 2007 Feb 15;109(4):668-74.

13. Wu AH, Tseng CC, Bernstein L. Hiatal hernia, reflux symptoms, body size, and risk of esophageal and gastric adenocarcinoma. Cancer.2003 Sep 1; 98(5):940-8.

14. Souza RF, Shewmake K, Terada LS, et al. Acid exposure activates the mitogenactivated protein kinase pathways in Barrett's oesophagus. Gastroenterology. 2002 Feb;122(2):299-307.

15. Theisen J, Peters JH, Fein M, et al. The mutagenic potential of duodenoesophageal reflux. Ann Surg.2005 Jan;241(1):63-8.

16. Lassen A, Hallas J, de Muckadell OB. Esophagitis: incidence and risk of esophageal adenocarcinoma--a population-based cohort study. Am J Gastroenterol. 2006 Jun;101(6):1193-9.

17. de Martel C, Llosa AE, Farr SM, et al. Helicobacter pylori infection and the risk of development of esophageal adenocarcinoma. J Infect Dis. 2005 Mar 1;191(5):761-7. 
18. Inomata $\mathrm{Y}$, Koike $\mathrm{T}$, Ohara $\mathrm{S}$, et al. Preservation of gastric acid secretion may be important for the development of gastroesophageal junction adenocarcinoma in Japanese people, irrespective of the H. pylori infection status. Am J Gastroenterol. 2006 May;101(5):926-33.

19. Devesa SS, Fraumeni JF Jr. The rising incidence of gastric cardia cancer. J Natl Cancer Inst.1999 May 5;91(9):747-9.

20. Derakhshan MH, Yazdanbod A, Sadjadi AR, et al. High incidence of adenocarcinoma arising from the right side of the gastric cardia in NW Iran. Gut. 2004 Sep;53(9):1262-6.

21. Kamangar F, Dawsey SM, Blaser MJ, et al. Opposing risks of gastric cardia and non cardia gastric adenocarcinomas associated with Helicobacter pylori seropositivity. J Natl Cancer Inst. 2006 Oct 18;98(20):1445-52.

22. Chow WH, Blaser MJ, Blot WJ, et al. An inverse relation between cagA+ strains of Helicobacter pylori infection and risk of esophageal and gastric cardia adenocarcinoma. Cancer Res. 1998 Feb 15;58(4):588-90.

23. Limburg P, Qiao Y, Mark S, et al. Helicobacter pylori seropositivity and subsite-specific gastric cancer risks in Linxian, China. J Natl Cancer Inst. 2001 Feb 7;93(3):226-33.

24. Kamangar F, Qiao YL, Blaser MJ, et al. Helicobacter pylori and esophageal and gastric cancers in a prospective study in China. Br J Cancer. 2007 Jan 15;96(1):172-6.

25. Eslick GD, Lim LL, Byles JE, et al. Association of Helicobacter pylori infection with gastric carcinoma: a meta-analysis. Am J Gastroenterol. 1999 Sep;94(9):2373-9.

26. Helicobacter and Cancer Collaborative Group. Gastric cancer and Helicobacter pylori: a combined analysis of 12 case control studies nested within prospective cohorts. Gut. 2001 Sep;49(3):347-53.

27. Ekstrom AM, Held M, Hansson LE, et al. Helicobacter pylori in gastric cancer established by CagA immunoblot as a marker of past infection. Gastroenterology. 2001 Oct;121(4):784-91.

28. Ye W, Chow WH, Lagergren J, et al. Risk of adenocarcinomas of the esophagus and gastric cardia in patients with gastroesophageal reflux diseases and after antireflux surgery. Gastroenterology. $2001 \mathrm{Dec} ; 121(6): 1286-93$.

29. Tran GD, Sun XD, Abnet CC, et al. Prospective study of risk factors for esophageal and gastric cancers in the Linxian general population trial cohort in China. Int J Cancer. 2005 Jan 20;113(3):456-63.

30. Hansen S, Vollset SE, Derakhshan MH, et al. Two distinct aetiologies of cardia cancer; evidence from premorbid serological markers of gastric atrophy and H. pylori status. Gut. 2007 Jul;56(7):918-25.

31. Sadjadi A, Malekzadeh R, Derakhshan MH, et al. Cancer occurrence in Ardabil: results of a population-based cancer registry from Iran. Int J Cancer.2003 Oct 20;107(1):113-8.

32. Annual report on cancer incidence, Ardabil Cancer Registry, Ardabil University of Medical Sciences; 2004.

33. International classification of disease for Oncology, $2^{\text {nd }}$ version, International Agency for Research on Cancer. Lyon.

34. Lauren P. The two histological main types of gastric carcinoma: diffuse and so-called intestinal-type carcinoma. An attempt at a histo-clinical classification. Acta Pathol Microbiol Scand. 1965;64:31-49. 
35. Nasseri-Moghaddam S, Malekzadeh R, Sotoudeh M, et al. Lower esophagus in dyspeptic Iranian patients: a prospective study. J Gastroenterol Hepatol. 2003 Mar;18(3):315-21.

36. SPSS for Windows, Version 14.0, SPSS Inc, Chicago, IL, USA.

37. Ohata H, Kitauchi S, Yoshimura N, et al. Progression of chronic atrophic gastritis associated with Helicobacter pylori infection increases risk of gastric cancer. Int $\mathrm{J}$ Cancer. 2004 Mar;109(1):138-43.

38. Watabe H, Mitsushima T, Yamaji Y, et al. Predicting the development of gastric cancer from combining Helicobacter pylori antibodies and serum pepsinogen status: a prospective endoscopic cohort study. Gut. 2005 Jun;54(6):764-8.

39. Uemura N, Okamoto S, Yamamoto S. H. pylori infection and the development of gastric cancer. Keio J Med. 2002 Dec;51 Suppl 2:63-8.

40. Komoto K, Haruma K, Kamada T, et al. Helicobacter pylori infection and gastric neoplasia: correlations with histological gastritis and tumor histology. Am J Gastroenterol.1998 Aug;93(8):1271-6.

41. Handa Y, Saitoh T, Kawaguchi M, et al. Association of Helicobacter pylori and diffuse type gastric cancer. J Gastroenterol. 1996 Nov;31 Suppl 9:29-32.

42. Dunbier A, Guilford P. Hereditary diffuse gastric cancer. Adv Cancer Res. 2001;83:55-65.

43. Sotoudeh M, Derakhshan MH, Abedi-Ardakani B. Critical role of Helicobacter pylori in the pattern of gastritis and carditis in residents of an area with high prevalence of gastric cardia cancer. Dig Dis Sci 2007 May 10; [Epub ahead of print]

44. Lindblad M, Rodriguez LA, Lagergren J. Body mass, tobacco and alcohol and risk of esophageal, gastric cardia, and gastric non-cardia adenocarcinoma among men and women in a nested case-control study. Cancer Causes Control. 2005 Apr;16(3):285-94.

45. Machida-Montani A, Sasazuki S, Inoue M, et al. Association of Helicobacter pylori infection and environmental factors in non-cardia gastric cancer in Japan. Gastric Cancer. 2004;7(1):46-53.

46. Solaymani-Dodaran M, Logan RF, West J, et al. Risk of oesophageal cancer in Barrett's oesophagus and gastro-oesophageal reflux. Gut. 2004 Aug;53(8):1070-4.

47. Veugelers PJ, Porter GA, Guernsey DL, et al. Obesity and lifestyle risk factors for gastroesophageal reflux disease, Barrett esophagus and esophageal adenocarcinoma. Dis esophagus. 2006;19(5):321-8.

48. Kimura K. Chronological changes of atrophic gastritis. Nippon Shokakibyo Gakkai Zasshi. 1973 Apr;70(4):307-15.

49. Kimura K, Satoh K, Ido K, et al. Gastritis in the Japanese stomach. Scand J Gastroenterol Supp.1996;214:17-20; discussion 21-3.

50. Vaananen H, Vauhkonen M, Helske T, et al. Non-endoscopic diagnosis of atrophic gastritis with a blood test. Correlation between gastric histology and serum levels of gastrin-17 and pepsinogen I: a multicentre study. Eur J Gastroenterol Hepatol. 2003 Aug;15(8):885-91.

51. Knight T, Wyatt J, Wilson A, et al. Helicobacter pylori gastritis and serum pepsinogen levels in a healthy population: development of a biomarker strategy for gastric atrophy in high risk groups. Br J Cancer.1996 Mar;73(6):819-24. 
Table 1: Frequency of risk factors of adenocarcinomas of non-cardia, oesophageal and cardia sub-sites, with matched controls

\begin{tabular}{|c|c|c|c|c|c|c|}
\hline & \multicolumn{2}{|c|}{ Non-Cardia } & \multicolumn{2}{|c|}{ Oesophageal } & \multicolumn{2}{|c|}{ Cardia } \\
\hline & Case (66) & Control (66) & Case (19) & Control (38) & Case (53) & Control (53) \\
\hline PG I/II [mean (SD)] & $2.01(1.01)$ & $3.46(1.73)$ & $4.76(2.00)$ & $3.43(1.92)$ & $3.39(2.23)$ & $4.19(2.46)$ \\
\hline \multicolumn{7}{|l|}{ Smoking } \\
\hline Ever smoker & $28(42.4 \%)$ & $15(22.7 \%)$ & $10(52.6 \%)$ & $9(23.7 \%)$ & $19(35.8 \%)$ & $12(22.6 \%)$ \\
\hline Non smoker & $38(57.6 \%)$ & $51(77.3 \%)$ & $9(47.4 \%)$ & $29(76.3 \%)$ & $34(64.2 \%)$ & $41(77.4 \%)$ \\
\hline \multicolumn{7}{|l|}{ GORD symptoms } \\
\hline$<1$ time per week & $50(75.8 \%)$ & $33(50.0 \%)$ & $2(10.5 \%)$ & $19(50.0 \%)$ & $25(47.2 \%)$ & $32(60.4 \%)$ \\
\hline $1-2$ times per week & $13(19.7 \%)$ & $23(34.8 \%)$ & $6(31.6 \%)$ & $15(39.5 \%)$ & $14(26.4 \%)$ & $17(32.1 \%)$ \\
\hline$>2$ times per week & $3(4.5 \%)$ & $10(15.2 \%)$ & $11(57.9 \%)$ & $4(10.5 \%)$ & $14(26.4 \%)$ & $4(7.5 \%)$ \\
\hline \multicolumn{7}{|l|}{ H.pylori Sero-status } \\
\hline Positive & $62(93.9 \%)$ & $49(74.2 \%)$ & $9(47.4 \%)$ & $28(73.7 \%)$ & $44(83.0 \%)$ & $39(73.6 \%)$ \\
\hline Negative & $4(6.1 \%)$ & $17(25.8 \%)$ & $10(52.6 \%)$ & $10(26.3 \%)$ & $9(17.0 \%)$ & $14(26.4 \%)$ \\
\hline \multicolumn{7}{|l|}{ Histological Subtype } \\
\hline Intestinal & $36(54.5 \%)$ & $\mathrm{n} / \mathrm{a}$ & $16(84.2 \%)$ & $\mathrm{n} / \mathrm{a}$ & $34(64.2 \%)$ & $\mathrm{n} / \mathrm{a}$ \\
\hline Diffuse & $25(37.9 \%)$ & $\mathrm{n} / \mathrm{a}$ & $1(5.3 \%)$ & $\mathrm{n} / \mathrm{a}$ & $16(30.2 \%)$ & $\mathrm{n} / \mathrm{a}$ \\
\hline Mixed / Unclassifiable & $5(7.6 \%)$ & $\mathrm{n} / \mathrm{a}$ & $2(10.5 \%)$ & $\mathrm{n} / \mathrm{a}$ & $3(5.7 \%)$ & $\mathrm{n} / \mathrm{a}$ \\
\hline
\end{tabular}


Table 2: Relationship between risk of non-cardia gastric cancer and pepsinogen I/ll, smoking, GORD symptoms and H.pylori sero-status

\begin{tabular}{|c|c|c|c|c|}
\hline & \multicolumn{2}{|l|}{ Univariate } & \multicolumn{2}{|c|}{ Multivariate } \\
\hline & Odds Ratio (95\% Cl) & P Value & Odds Ratio (95\% Cl) & P Value \\
\hline \multicolumn{5}{|l|}{ PG Ratio quintiles } \\
\hline $5^{\text {th }}: 5.125-7.445$ & 1.00 & & 1.00 & \\
\hline $4^{\text {th }}: 3.607-4.793$ & $3.11(0.62-15.58)$ & 0.168 & $3.50(0.45-27.37)$ & 0.233 \\
\hline $3^{\text {rd }:}: 2.707-3.560$ & $4.77(1.07-21.21)$ & 0.040 & $6.48(0.78-54.01)$ & 0.084 \\
\hline $2^{\text {nd }}: 2.092-2.701$ & $7.75(1.81-33.16)$ & 0.006 & $9.08(1.10-75.29)$ & 0.041 \\
\hline $1^{\text {st }}: 0.189-2.011$ & $15.76(3.92-63.43)$ & 0.000 & $21.47(2.90-158.76)$ & 0.003 \\
\hline \multicolumn{5}{|l|}{ Smoking } \\
\hline Non smoker & 1.00 & & 1.00 & \\
\hline Ever smoker & $2.22(1.11-4.46)$ & 0.025 & $5.83(2.11-16.11)$ & 0.001 \\
\hline \multicolumn{5}{|l|}{ GORD symptoms } \\
\hline$<1$ time per week & 1.00 & & 1.00 & \\
\hline $1-2$ times per week & $0.44(0.20-0.96)$ & 0.039 & $0.31(0.11-0.85)$ & 0.023 \\
\hline$>2$ times per week & $0.44(0.17-1.10)$ & 0.079 & $0.91(0.18-4.64)$ & 0.913 \\
\hline \multicolumn{5}{|c|}{ H.pylori Sero-status } \\
\hline Negative & 1.00 & & 1.00 & \\
\hline Positive & $2.22(1.11-4.46)$ & 0.025 & $1.53(0.57-4.14)$ & 0.401 \\
\hline
\end{tabular}


Table 3: Relationship between risk of oesophageal adenocarcinoma and pepsinogen I/II, smoking, GORD symptoms and H.pylori sero-status

\begin{tabular}{|c|c|c|c|c|}
\hline & \multicolumn{2}{|l|}{ Univariate } & \multicolumn{2}{|l|}{ Multivariate } \\
\hline & Odds Ratio (95\% Cl) & P Value & Odds Ratio (95\% Cl) & P Value \\
\hline \multicolumn{5}{|l|}{ PG Ratio quintiles } \\
\hline $5^{\text {th }}: 4.482-9.409$ & 1.00 & & 1.00 & \\
\hline $4^{\text {th }}: 3.395-4.266$ & $0.35(0.07-1.72)$ & 0.197 & $0.40(0.05-3.29)$ & 0.397 \\
\hline $3^{\text {rd }}: 2.611-3.271$ & $0.35(0.07-1.72)$ & 0.197 & $0.26(0.03-2.22)$ & 0.217 \\
\hline $2^{\text {nd }}: 1.978-2.483$ & $0.29(0.06-1.46)$ & 0.132 & $0.57(0.08-4.11)$ & 0.573 \\
\hline $1^{\text {st }}: 1.155-1.959$ & $0.26(0.05-1.49)$ & 0.131 & $0.41(0.05-3.69)$ & 0.427 \\
\hline \multicolumn{5}{|l|}{ Smoking } \\
\hline Non smoker & 1.00 & & 1.00 & \\
\hline Ever smoker & $4.70(1.54-14.34)$ & 0.007 & $4.56(1.01-20.68)$ & 0.049 \\
\hline \multicolumn{5}{|l|}{ GORD symptoms } \\
\hline$<1$ time per week & 1.00 & & 1.00 & \\
\hline $1-2$ times per week & $2.60(0.65-10.36)$ & 0.175 & $1.73(0.33-9.11)$ & 0.520 \\
\hline$>2$ more times per week & $28.05(4.74-165.91)$ & 0.001 & $12.46(1.80-86.47)$ & 0.011 \\
\hline \multicolumn{5}{|l|}{ H.pylori Sero-status } \\
\hline Negative & 1.00 & & 1.00 & \\
\hline Positive & $0.25(0.08-0.75)$ & 0.014 & $0.43(0.10-1.91)$ & 0.268 \\
\hline
\end{tabular}


Table 4: Relationship between risk of gastric cardia cancer and pepsinogen I /II, smoking, GORD symptoms and H.pylori sero-status

\begin{tabular}{|c|c|c|c|c|}
\hline & \multicolumn{2}{|l|}{ Univariate } & \multicolumn{2}{|c|}{ Multivariate } \\
\hline & Odds Ratio (95\% Cl) & $P$ Value & Odds Ratio $(95 \% \mathrm{Cl})$ & P Value \\
\hline \multicolumn{5}{|l|}{ PG Ratio quintiles } \\
\hline $5^{\text {th }}: 6.008-11.586$ & 1.00 & & 1.00 & \\
\hline $4^{\text {th }}: 3.848-6.004$ & $1.10(0.50-2.40)$ & 0.817 & $0.92(0.37-2.26)$ & 0.852 \\
\hline $3^{\text {rd }}: 3.062-3.734$ & $0.50(0.20-1.25)$ & 0.138 & $0.62(0.23-1.71)$ & 0.355 \\
\hline $2^{\text {nd }}: 2.378-3.017$ & $0.50(0.20-1.25)$ & 0.138 & $0.49(0.18-1.38)$ & 0.177 \\
\hline $1^{\text {st }}: 0.479-2.370$ & $2.77(1.36-5.63)$ & 0.005 & $3.92(1.77-8.67)$ & 0.001 \\
\hline \multicolumn{5}{|l|}{ Smoking } \\
\hline Non smoker & 1.00 & & 1.00 & \\
\hline Ever smoker & $1.70(0.79-3.67)$ & 0.175 & $1.40(0.56-3.51)$ & 0.476 \\
\hline \multicolumn{5}{|l|}{ GORD symptoms } \\
\hline$<1$ time per week & 1.00 & & 1.00 & \\
\hline $1-2$ times per week & $0.95(0.40-2.29)$ & 0.915 & $1.47(0.54-4.00)$ & 0.451 \\
\hline$>2$ more times per week & $3.15(1.17-8.49)$ & 0.024 & $10.08(2.29-44.36)$ & 0.002 \\
\hline \multicolumn{5}{|l|}{ H.pylori Sero-status } \\
\hline Negative & 1.00 & & 1.00 & \\
\hline Positive & $1.46(0.68-3.14)$ & 0.332 & $2.42(0.84-7.02)$ & 0.103 \\
\hline
\end{tabular}


Table 5: Relationship between GORD symptoms and risk of gastric cardia cancer in atrophic versus non-atrophic subjects

\begin{tabular}{|c|c|c|c|c|c|}
\hline \multirow[t]{2}{*}{ PG I/II } & \multirow{2}{*}{$\begin{array}{l}\text { GORD } \\
\text { symptoms }\end{array}$} & \multicolumn{2}{|c|}{ Cardia cancer } & \multirow{2}{*}{$\begin{array}{l}\text { Fisher's Exact test } \\
\text { P value (two-sided) }\end{array}$} & \multirow{2}{*}{$\begin{array}{c}\text { OR } \\
(95 \% \mathrm{Cl})\end{array}$} \\
\hline & & Case & Control & & \\
\hline \multirow{3}{*}{ Atrophic } & $>2$ / week & 1 & 0 & & \\
\hline & $0-2$ / week & 24 & 12 & 1.000 & NA \\
\hline & Total & 25 & 12 & & \\
\hline \multirow{3}{*}{ Non-atrophic } & $>2$ / week & 13 & 4 & & \\
\hline & $0-2$ / week & 15 & 37 & 0.001 & $8.02(2.25-28.58)$ \\
\hline & Total & 28 & 41 & & \\
\hline
\end{tabular}


Figure legends:

Fig 1: Relationship between severity of atrophic gastritis, expressed by serum PG I/II and risk of gastric cancer at non-cardia (A) and cardia subsites (B). The first quintile of PG I/II indicates greatest degree of atrophy and $5^{\text {th }}$ quintile least atrophy.

Fig 2: This presents the PG $\mathrm{I} / \mathrm{Il}$ values in the individual patients with oesophageal, cardia and non-cardia cancers. The cardia cancers are grouped according to histological subtype and frequency of GORD symptoms. Atrophy is indicated by PG I/II values of $<2.5$ (broken line). 


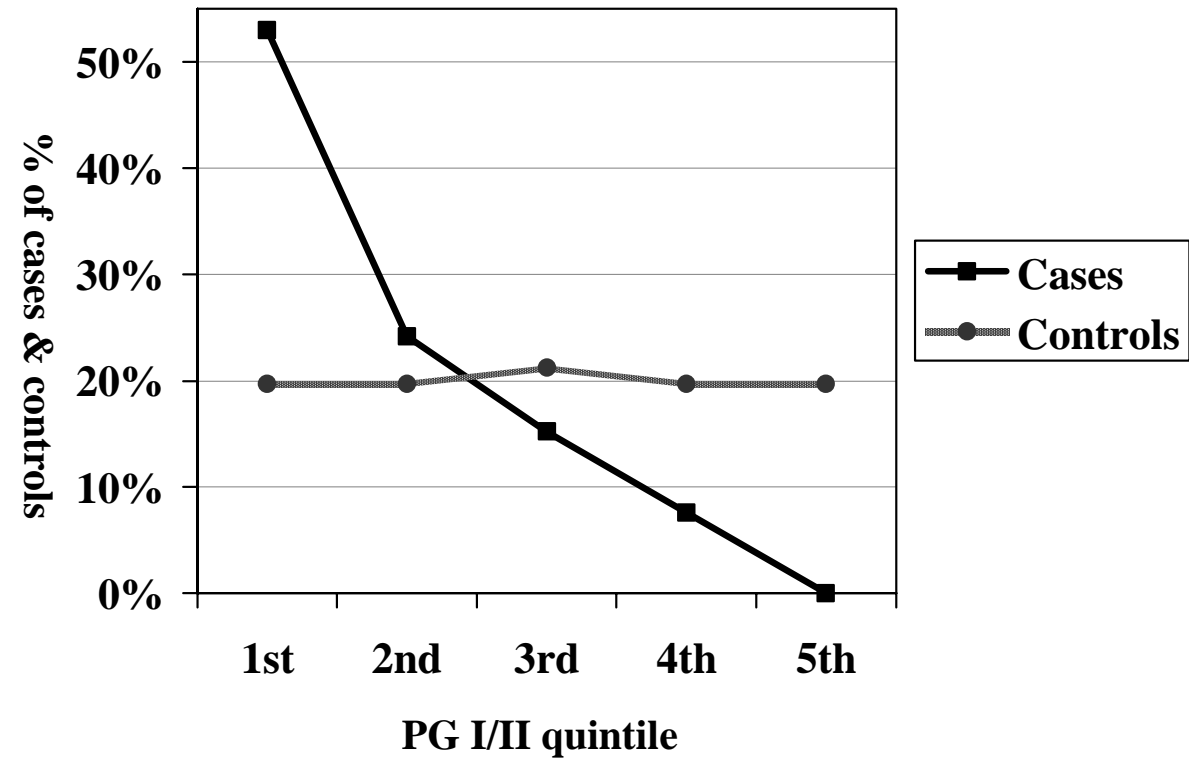

Fig 1a: Gastric non-cardia cancer

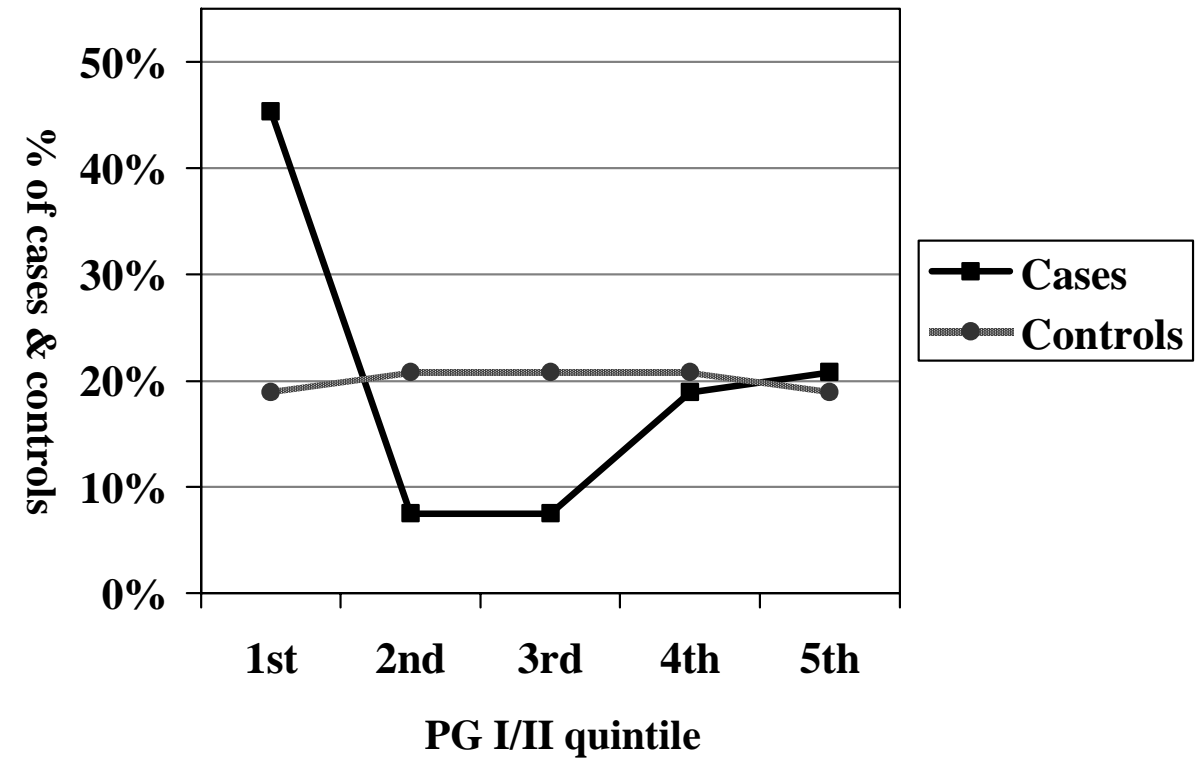

Fig 1b: Gastric cardia cancer 


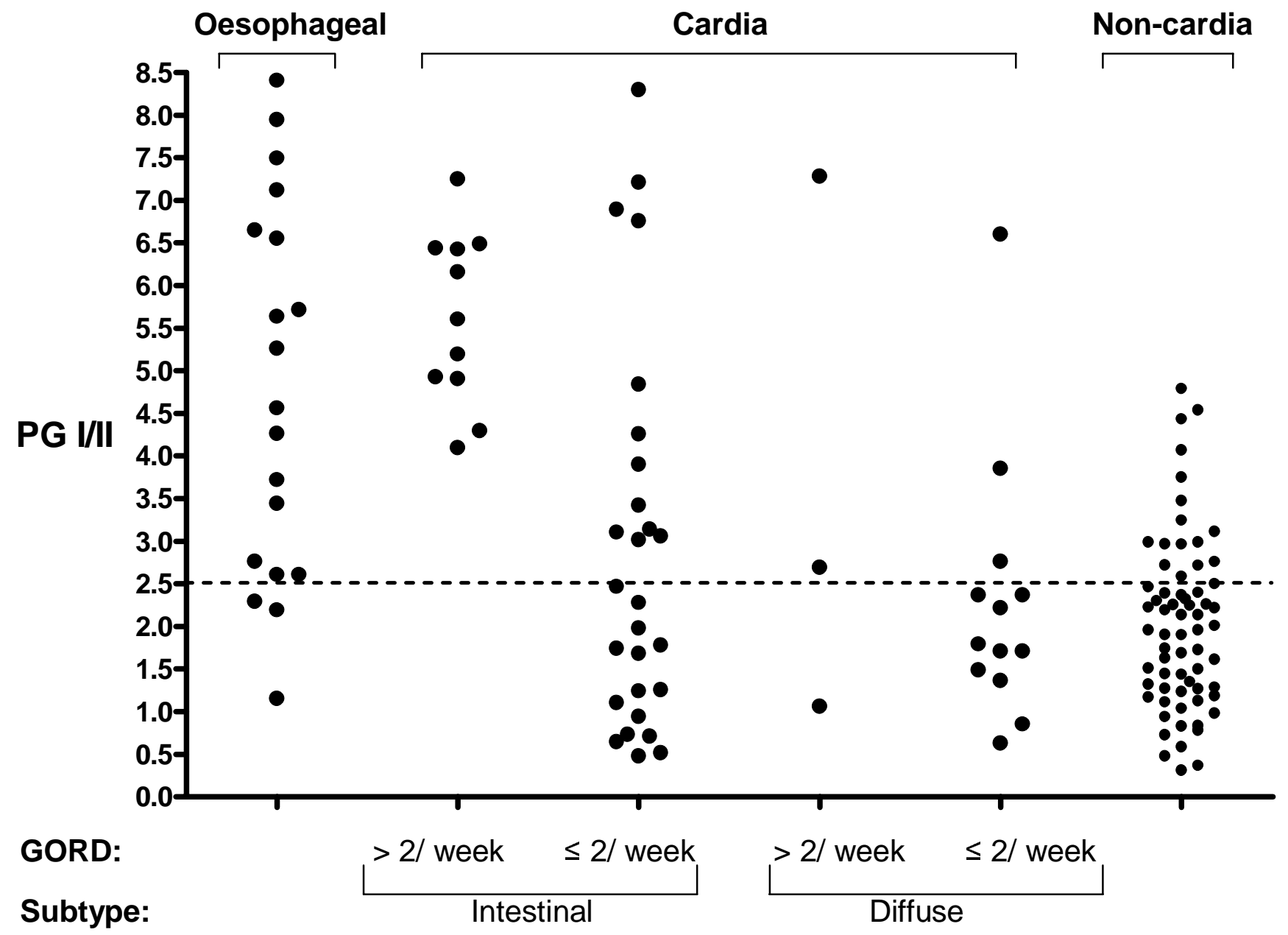

